\title{
Desvenlafaxine in major depressive disorder: an evidence-based review of its place in therapy
}

This article was published in the following Dove Press journal:

Core Evidence

23 June 2009

Number of times this article has been viewed

\section{Daniel Z Lieberman Suena $\mathrm{H}$ Massey \\ Department of Psychiatry and Behavioral Sciences, George Washington University School of Medicine and Health Sciences, Washington, DC, USA}

Correspondence: Daniel Z Lieberman Department of Psychiatry and Behavioral Sciences, George Washington University School of Medicine and Health Sciences, Washington, DC, USA

Email dlieberman@mfa.gwu.edu
Introduction: Desvenlafaxine, the active metabolite of venlafaxine, is a serotonin norepinephrine reuptake inhibitor (SNRI) recently approved for the treatment of major depressive disorder. It is one of only three medications in this class available in the United States.

Aims: The objective of this article is to review the published evidence for the safety and efficacy of desvenlafaxine, and to compare it to other antidepressants to delineate its role in the treatment of depression.

Evidence review: At the recommended dose of $50 \mathrm{mg}$ per day the rate of response and remission was similar to other SNRIs, as was the adverse effect profile. The rate of discontinuation was no greater than placebo, and a discontinuation syndrome was not observed at this dose. Higher doses were not associated with greater efficacy, but they did lead to more side effects, and the use of a taper prior to discontinuation. The most common side effects reported were insomnia, somnolence, dizziness, and nausea. Some subjects experienced clinically significant blood pressure elevation.

Place in therapy: Like duloxetine, desvenlafaxine inhibits the reuptake of both norepinephrine and serotonin at the starting dose. Dual reuptake inhibitors have been shown to have small but statistically significantly greater rates of response and remission compared to selective serotonin reuptake inhibitors, and they have also shown early promise in the treatment of neuropathic pain. Desvenlafaxine may prove to be a valuable treatment option by expanding the limited number of available dual reuptake inhibitors.

Keywords: desvenlafaxine, depression, reuptake inhibitors, norepinephrine, serotonin

\section{Core evidence outcomes summary for desvenlafaxine in depression}

\begin{tabular}{|c|c|c|}
\hline Outcome measure & Evidence & Implications/Comments \\
\hline \multicolumn{3}{|l|}{ Disease-oriented evidence } \\
\hline $\begin{array}{l}\text { Significant reduction in depression } \\
\text { symptoms (HAMDI7) }\end{array}$ & Substantial & $\begin{array}{l}\text { Desvenlafaxine effectively treats } \\
\text { depression at } 50-100 \mathrm{mg} \text { per day. }\end{array}$ \\
\hline $\begin{array}{l}\text { Discontinuation due to adverse events } \\
\text { in the } 50 \mathrm{mg} \text { group was similar to } \\
\text { placebo }\end{array}$ & Substantial & $\begin{array}{l}\text { Desvenlafaxine } 50-100 \mathrm{mg} \text { per day is safe } \\
\text { and well-tolerated. }\end{array}$ \\
\hline $\begin{array}{l}\text { No serious symptoms associated with } \\
\text { discontinuation of } 50 \mathrm{mg} \text { dose (DESS) }\end{array}$ & Clear & $\begin{array}{l}\text { Desvenlafaxine } 50 \mathrm{mg} \text { can be } \\
\text { discontinued without a taper. }\end{array}$ \\
\hline $\begin{array}{l}\text { Reduction in various indices of chronic } \\
\text { pain (VAS-PI) }\end{array}$ & Moderate & $\begin{array}{l}\text { Desvenlafaxine may be useful in treating } \\
\text { chronic pain, however the clinical trials were } \\
\text { not designed to measure efficacy for pain. }\end{array}$ \\
\hline \multicolumn{3}{|l|}{ Patient-oriented evidence } \\
\hline Reduction in disability indices (SDS) & Clear & $\begin{array}{l}\text { Desvenlafaxine produced a significant } \\
\text { reduction in disability due to depression. }\end{array}$ \\
\hline $\begin{array}{l}\text { Improvement in psychological } \\
\text { well-being indices (WHO-5) }\end{array}$ & Clear & $\begin{array}{l}\text { Desvenlafaxine significantly improved } \\
\text { psychological well-being. }\end{array}$ \\
\hline
\end{tabular}

submit your manuscript | www.dovepress.com

Dovepress 


\section{Scope, aims, and objectives}

Desvenlafaxine (DVS) is the most recently approved medication for the treatment of major depressive disorder. DVS is chemically unrelated to tricyclic, tetracyclic, or other available antidepressants (with the exception of venlafaxine), and is classified as a dual-acting serotonin (5-HT) and norepinephrine (NE) reuptake inhibitor (SNRI). Nonclinical studies have demonstrated that it inhibits the neuronal uptake of both 5-HT and NE and, to a lesser degree, dopamine. It does not have any monoamine oxidase inhibitory activity, and it shows virtually no affinity for rat brain muscarinic cholinergic, H1-histaminergic, or alpha-1 adrenergic receptors.

The objective of this article is to review the published evidence for the safety and efficacy of DVS that led to its approval by the US Food and Drug Administration (FDA). Additionally, DVS is compared to other antidepressants in order to delineate the advantages and disadvantages of this drug, and its appropriate place in the treatment of depression.

\section{Methods}

The English language medical literature was searched in August 2008 using the following databases. Search terms used were "desvenlafaxine OR DVS." Nonhuman and in vitro studies were excluded from the search. Results are shown in Table 1.

- PubMed, http://www.ncbi.nlm.nih.gov/sites/entrez

- The Cochrane Library, http://www.mrw.interscience. wiley.com/cochrane

- EMBASE, http://www.datastarweb.com/

- BIOSIS, http://www.datastarweb.com/

Table I Evidence base included in the review

\begin{tabular}{lll}
\hline Category & \multicolumn{2}{l}{ Number of records } \\
\cline { 2 - 3 } & Full papers & Abstracts \\
\hline Initial search & 20 & 6 \\
$\quad$ Records excluded & 14 & 2 \\
$\quad$ Records included & 6 & 4 \\
Level I clinical evidence & 0 & 0 \\
(systematic review, meta-analysis) & & \\
Level 2 clinical evidence (RCT) & 6 & 4 \\
Level $\geq 3$ clinical evidence & & \\
$\quad$ Trials other than RCT & 0 & 0 \\
$\quad$ Case studies & 0 & 0 \\
Economic evidence & 0 & 0 \\
Total records included & 6 & 4 \\
\hline
\end{tabular}

Abbreviation: $\mathrm{RCT}$, randomized controlled trials.
- National Institute for Health and Clinical Evidence (NICE), http://www.nice.org.uk/

- York University Centre for Reviews and Dissemination databases, http://www.crd.york.ac.uk/crdweb

\section{Disease overview}

Major depressive disorder (MDD) is diagnosed based on the presence of a constellation of signs and symptoms that are characteristic of the illness. This type of phenomenological definition differs significantly from etiological diagnoses in which a disease is diagnosed by the presence of a causative agent (ie, mycobacteria in tuberculosis) or specific pathophysiological abnormality (ie, plaques and tangles in Alzheimer's disease). Nevertheless, using standardized criteria, the reliability of the diagnosis of major depressive disorder is high. ${ }^{1}$ Like most psychiatric disorders, the etiology and pathophysiology of major depressive disorder is not well understood, however, we do know that it is highly prevalent, is often disabling, and responds to both somatic and psychotherapeutic treatment.

The essential feature of a major depressive episode is a period of at least two weeks during which there is either depressed mood or the loss of interest or pleasure in nearly all activities. ${ }^{2}$ In children and adolescents, the mood may be irritable rather than sad. The individual must also experience at least four additional symptoms drawn from a list that includes changes in appetite, weight, sleep, or psychomotor activity; decreased energy; feelings of worthlessness or guilt; difficulty thinking, concentrating, or making decisions; and recurrent thoughts of death, suicidal ideation, plans, or attempts. A symptom must either be newly present or must have clearly worsened compared with the individual's pre-episode status.

The symptoms must persist for most of the day, nearly every day, for at least two consecutive weeks. The episode must be accompanied by clinically significant distress or impairment in social, occupational, or other important areas of functioning. Diagnostic criteria are listed in Table 2.

For some individuals with milder episodes, functioning may appear to be normal but requires markedly increased effort. The mood in a major depressive episode is often described by the person as depressed, sad, hopeless, discouraged, or "down in the dumps". In some cases, sadness may be denied at first, but may subsequently be elicited by interview (eg, by pointing out that the individual looks as if he or she is about to cry). Some individuals complain of feeling "flat", having no feelings, or feeling anxious. At times, the presence of a depressed mood can be inferred from the 
Table 2 Diagnostic criteria for major depressive disorder. Copyright @ 1994. American Psychiatric Association. Diagnostic and statistical manual of mental disorders. 4th edition. Washington, DC: American Psychiatric Association, 1994

Presence of five out of the following symptoms, including depressed mood:

Depressed mood most of the day, nearly every day, as indicated by either subjective report (eg, feels sad or empty) or observation made by others (eg, appears tearful). (In children and adolescents, this may be characterized as an irritable mood).

Markedly diminished interest or pleasure in all, or almost all, activities most of the day, nearly every day.

Significant weight loss when not dieting or weight gain (eg, a change of more than $5 \mathrm{~kg}$ of body weight in a month), or decrease or increase in appetite nearly every day.

Insomnia or hypersomnia nearly every day.

Psychomotor agitation or retardation nearly every day.

Fatigue or loss of energy nearly every day.

Feelings of worthlessness or excessive or inappropriate guilt nearly every day.

Diminished ability to think or concentrate, or indecisiveness, nearly every day.

Recurrent thoughts of death (not just fear of dying), recurrent suicidal ideation without a specific plan, or a suicide attempt or a specific plan for committing suicide.

person's facial expression and demeanor. Some patients emphasize somatic complaints (eg, bodily aches and pains) rather than reporting feelings of sadness. Many individuals report or exhibit increased irritability (eg, persistent anger, a tendency to respond to events with angry outbursts or blaming others, or an exaggerated sense of frustration over minor matters).

\section{Epidemiology}

MDD is a leading cause of disability due to its high prevalence and the severity of functional impairment associated with its symptoms. ${ }^{3}$ Estimates of the general population prevalence of mental disorders in the United States have been most extensively measured using structured lay interviews. The first such instrument was the Diagnostic Interview Schedule, ${ }^{4}$ which was developed for use in the Epidemiologic Catchment Area (ECA) study. ${ }^{5}$ Using the Diagnostic and Statistical Manual of Mental Disorders, Third Edition (DSM-III) criteria, ${ }^{6} \mathrm{MDD}$ prevalence estimates in the ECA sites were $3.0 \%$ to $5.9 \%$ for lifetime and $1.7 \%$ to $3.4 \%$ for 12 -month estimates. $^{7}$

A decade later a second nationally representative survey using a method similar to the ECA was carried out called the National Comorbidity Survey (NCS) ${ }^{8}$ Unlike the ECA, the NCS used memory priming strategies and respondent motivation techniques which resulted in prevalence estimates that were substantially higher: $14.9 \%$ for lifetime and $8.6 \%$ for 12-month estimates. ${ }^{9}$

Since the NCS was conducted there has been an increasing awareness of depression. A number of large national programs to promote knowledge about depression have been launched, ${ }^{10,11}$ and there has been a large increase in the number of Americans who take antidepressant medications. ${ }^{12}$ Some believed that depression was being overdiagnosed, and that the prevalence of MDD had been overestimated in the ECA and NCS studies because of the possibility that a substantial proportion of respondents classified as cases had clinically insignificant manifestations of the disease despite meeting the symptom criteria. ${ }^{13}$ This concern, that depression was being overdiagnosed, led to changes in the diagnostic criteria in the fourth edition of the Diagnostic and Statistical Manual of Mental Disorders (DSM-IV). Symptoms used to make the diagnosis were required to cause clinically significant distress or impairment in social, occupational, or some other important area of functioning. ${ }^{2}$

The National Comorbidity Survey Replication (NCS-R), a new national survey of mental disorders, was conducted in 2001-2002, in which DSM-IV criteria were used, including the requirement of clinical significance. ${ }^{14} \mathrm{In}$ this face-to-face study of 9,000 adults, age 18 years or older, results similar to the NCS were found. The prevalence of depression for lifetime was $16.2 \%$, and for 12 -month it was $6.6 \%$. Using the clinical significance classification, the severity of symptoms was evaluated: $10.4 \%$ of the cases were mild, $38.6 \%$ moderate, $38.0 \%$ severe, and $12.9 \%$ very severe.

\section{Disease burden}

The burden of disease can be measured in a number of different ways. One of the simpler measures is the mortality associated with the illness. From a clinical standpoint, the mortality associated with depression is distressingly high. For example, a meta-analysis of 23 papers from nine countries found that depressed persons had a suicide risk 20 times that of the general population. ${ }^{15}$ 
From an epidemiologic point of view however, death is a relatively rare outcome of depression. In the World Health Organization estimates of mortality and burden of disease for 2002, depression, as a specific illness, was not one of the top 15 causes of global mortality. ${ }^{16}$ Self-inflicted injuries, which include suicide from all mental illnesses and all other causes, ranked 14 . The top three were ischemic heart disease, cerebrovascular disease, and lower respiratory infections.

Another way of measuring the burden of a disease is by measuring the disability that it causes. Conditions that are the chief causes of disability are generally very different from leading causes of death, and have been mostly ignored in debates about public health priorities. Because depression does not kill those who suffer from it, and because it is a chronic illness with serious symptoms, the burden, as measured by years of life lived with a disability (YLD), is high. The Global Burden of Disease Study ${ }^{17}$ found that unipolar major depression was the leading cause of worldwide YLD in 1990 , accounting for $10.7 \%$ of the total. ${ }^{18}$ The second leading cause, iron-deficiency anemia, was responsible for $4.7 \%$ of YLD, less than half of that caused by depression. The authors note that the massive but largely unrecognized burden of mental illness is clearly evident in this study, with neuropsychiatric disorders filling five of the top ten causes of disability. These included unipolar major depression, alcohol use, bipolar disorder, schizophrenia, and obsessive compulsive disorder.

Disability adjusted life years (DALYs) is a measurement that blends mortality and disability in order to provide a more comprehensive representation of the burden of an illness. ${ }^{19}$ DALYs are calculated by starting with years of life lost due to an illness, eg, mortality. An adjustment is made for the value of time lived at different ages reflecting the dependence of the young and the elderly on adults. The time lived with a disability is made comparable with the time lost due to premature mortality by assigning a severity weight between 0 and 1 , in which a year with no disability is weighted 0 , and a year lost due to premature mortality is weighted 1. For example, a Class 1 disability, which has a weight of 0.096, is represented by limited ability to perform at least one activity in one of the following areas: recreation, education, procreation, or occupation. By contrast, a Class 4 disability, which has a weight of 0.6 , is represented by limited ability to perform most activities in all of the following areas: recreation, education, procreation, and occupation.

In 2002 unipolar depressive disorder ranked fourth as a leading cause of DALYs globally. ${ }^{16}$ The top three causes were perinatal conditions, lower respiratory infections, and
HIV/AIDS. Projections looking forward to 2030 predict depression rising to the second leading cause of DALYs, with HIV/AIDS as the leading cause, and ischemic heart disease rising to third. Overall, despite the relatively low mortality associated with depression, it is a serious illness that is one of the largest contributors to the global burden of disease.

\section{Current therapy options}

\section{Treatment guidelines}

The American Psychiatric Association (APA) guideline for the treatment of MDD provides evidence-based recommendations for the assessment and treatment of adults with depression. ${ }^{20}$ Treatment may be divided into four phases corresponding to the natural history of MDD: acute, continuation, maintenance, and discontinuation. The goal during the acute phase is remission of symptoms. Other phases are centered on maintenance of gains and the prevention of relapse.

The guidelines extensively discuss the use of antidepressant medication in the treatment of MDD, but also note that in addition to pharmacotherapy, psychiatric management should incorporate a broad array of interventions that include a diagnostic evaluation, an evaluation of the safety of the patient and others, an evaluation of the level of functional impairment, determination of the best treatment setting, establishing and maintaining a therapeutic alliance, providing education to patients and families, enhancing treatment adherence, and working with patients to address early signs of relapse.

The selection of a medication is influenced by a number of factors including the nature and severity of a patient's symptoms, as well as the patient's preference. Antidepressant medications that have been shown to be effective are listed in Table 3. The guidelines conclude that the overall effectiveness of antidepressant medications is comparable between classes and within classes of medications. Therefore, the initial selection of an antidepressant should be based on past response, family history of response, anticipated side effects, and cost. Implementation of pharmacotherapy may require titration from a low starting dose to the full therapeutic dose at a rate dependent on patient tolerability and co-morbid medical conditions. Patients who have started an antidepressant need to be closely monitored for worsening of symptoms and any adverse effects which may arise.

The APA guidelines provide a broad discussion of interventions that are considered to be well-supported by clinical evidence. More specific treatment guidance can 
Table 3 FDA-approved medications for the treatment of major depressive disorder

\begin{tabular}{|c|c|c|}
\hline & Starting dose (mg/day) & Target daily dose (mg/day) \\
\hline \multicolumn{3}{|l|}{ SSRIs } \\
\hline citalopram $\left(\right.$ Celexa $\left.{ }^{\circledR}\right)$ & 20 & $20-60$ \\
\hline fluoxetine $\left(\operatorname{Prozac}^{\circledR}\right)$ & 20 & $20-60$ \\
\hline paroxetine $\left(\right.$ Paxil $^{\circledR}$, Paxil CR $^{\circledR}$, Pexeva $^{\circledR}$ ) & 20 & $20-60$ \\
\hline sertraline $\left(\right.$ Zoloft $\left.^{\circledR}\right)$ & 50 & $50-200$ \\
\hline escitalopram (Lexapro ${ }^{\circledR}$ ) & 10 & $10-30$ \\
\hline \multicolumn{3}{|l|}{ Tricyclics and tertracyclics } \\
\hline amitriptyline $\left(\right.$ Elavi $^{\circledR}$, Endep $\left.^{\circledR}\right)$ & $25-50$ & $100-300$ \\
\hline clomipramine $\left(\right.$ Anafranil ${ }^{\circledR}$ ) & 25 & $100-250$ \\
\hline doxepin (Adapin ${ }^{\circledR}$, Sinequan $^{\circledR}$ ) & $25-50$ & $100-300$ \\
\hline imipramine (Tofranil ${ }^{\circledR}$ ) & $25-50$ & $100-300$ \\
\hline trimipramine $\left(\right.$ Surmonti $\left.{ }^{\circledR}\right)$ & $25-50$ & $100-300$ \\
\hline desipramine $\left(\right.$ Norpramin $\left.^{\circledR}\right)$ & $25-50$ & $100-300$ \\
\hline nortriptyline $\left(\right.$ Pamelor $^{\circledR}$, Aventy $^{\circledR}$ ) & 25 & $50-200$ \\
\hline protriptyline $\left(\right.$ Vivactil $\left.^{\circledR}\right)$ & 10 & $15-60$ \\
\hline amoxapine $\left(\right.$ Asendin $\left.{ }^{\circledR}\right)$ & 50 & $100-400$ \\
\hline maprotiline $\left(\right.$ Ludiomi $\left.^{\circledR}\right)$ & 50 & $100-225$ \\
\hline \multicolumn{3}{|l|}{$\begin{array}{l}\text { Dopamine-norepinephrine } \\
\text { reuptake inhibitors }\end{array}$} \\
\hline Bupropion (Wellbutrin ${ }^{\circledR}$ ) & 150 & $150-300$ \\
\hline $\begin{array}{l}\text { Bupropion, sustained release } \\
\left(\text { Wellbutrin } \mathrm{SR}^{\circledR} \text {, Budeprion } \mathrm{SR}^{\circledR} \text { ) }\right.\end{array}$ & 150 & $150-300$ \\
\hline $\begin{array}{l}\text { bupropion extended release } \\
\text { (Wellbutrin } X L^{\circledR}, \text { Budeprion } X^{\circledR}{ }^{\circledR} \text { ) }\end{array}$ & 150 & $150-300$ \\
\hline \multicolumn{3}{|l|}{ Serotonin-norepinephrine } \\
\hline duloxetine (Cymbalta $\left.{ }^{\circledR}\right)$ & 30 & 60 \\
\hline venlafaxine XR (Effexor XR ${ }^{\circledR}$ ) & 37.5 & $75-225$ \\
\hline desvenlafaxine ER (Pristiq ${ }^{\circledR}$ ) & 50 & $50-100$ \\
\hline \multicolumn{3}{|l|}{ Serotonin modulators } \\
\hline nefazadone $\left(\right.$ Serzone $\left.{ }^{\circledR}\right)$ & 50 & $150-300$ \\
\hline trazadone $\left(\right.$ Desyrel $\left.{ }^{\circledR}\right)$ & 50 & $50-300$ \\
\hline \multicolumn{3}{|l|}{ Norepinephrine-serotonin modulators } \\
\hline mirtazapine $\left(\right.$ Remeron ${ }^{\circledR}$ ) & 15 & 45 \\
\hline \multicolumn{3}{|l|}{ Monoamine oxidase inhibitors } \\
\hline tranylcypromine (Parnate ${ }^{\circledR}$ ) & 10 & $30-60$ \\
\hline phenelzine $\left(\mathrm{Nardil}^{\circledR}\right)$ & 15 & $15-90$ \\
\hline selegeline transdermal $\left(\right.$ Emsam $\left.^{\circledast}\right)$ & 6 & $9-12$ \\
\hline isocarboxazid (Marplan $\left.{ }^{\circledR}\right)$ & 20 & $40-60$ \\
\hline
\end{tabular}

Abbreviations: CR, controlled release; FDA, US Food and Drug Administration; SSRIs, selective serotonin reuptake inhibitors; XR, extended release.

be obtained from the Texas Medication Algorithm Project (TMAP), which provides step-by-step recommendations for medication selection. An evaluation of the performance of the algorithm demonstrated superior outcomes compared to treatment as usual for patents with moderate to severe depression..$^{21}$
TMAP treatment consists of a total of seven stages for nonpsychotic MDD and five for psychotic MDD. Each stage represents management of increasing levels of treatment resistance. For nonpsychotic MDD, Stage 1 involves monotherapy that can include a selective serotonin re-uptake inhibitor (SSRI), bupropion extended release (ER), nefazodone, a serotonin 
norepinephrine reuptake inhibitor (SNRI), or mirtazapine. DVS was not included in the algorithm because it had not been released at the time the algorithm was developed.

Partial response at any stage leads to a recommendation of augmentation. Medications shown to be efficacious when used to augment antidepressant treatment include lithium, thyroid hormone, buspirone, and bupropion. In the absence of a response, or failure of an augmentation strategy, a switch is recommended to either an antidepressant in the same class or in a different class (Stage 2). It is also acceptable to switch immediately to another antidepressant in the same or different class after partial response with initial monotherapy.

Stage 3 involves the use of an older generation antidepressant, either a tricyclic antidepressant (TCA) or a monoamine oxidase inhibitor (MAOI). Because tricyclic antidepressants can be lethal in overdose, ${ }^{22}$ and the safe use of MAOIs involves adherence to a low-tyramine diet, ${ }^{23}$ these two classes are usually not used as first line agents. If either a TCA or MAOI is ineffective in bringing about remission, lithium augmentation is recommended (Stage 4) if it has not been tried previously. Stage 5 involves combinations of antidepressants, and Stage 6 is electroconvulsive therapy (ECT). If ECT is ineffective or contraindicated, use of medications which have not been approved for use in the treatment of MDD can be tried (Stage 7). These include, but are not limited to lamotrigine, fluvoxamine, and olanzapine.

Psychotic major depression (PMD) is a subtype of MDD that is defined by the presence of delusions or hallucinations occurring in the context of a severe depressive episode (DSM-IV). PMD is associated with greater illness severity, impairment, comorbidity, and mortality when compared with MDD. Furthermore, PMD patients tend to have higher rates of illness chronicity, relapse, and hospitalization. Typically these patients require adjunctive treatment with antipsychotic medication or ECT. ${ }^{24}$ According to the Texas Medication Algorithm, the first line of treatment for depression with psychotic features includes a combination of an antidepressant with an antipsychotic medication (Stage 1). If only a partial response is achieved a TCA should be tried (or a non-TCA antidepressant if a TCA was used in Stage 1). If remission is still not achieved, ECT is indicated, where appropriate. If this is unsuccessful, lithium augmentation should be tried, and finally combinations of more than one antidepressant with an antipsychotic medication.

\section{Comparator drugs}

Before 1980, antidepressant treatment consisted primarily of the TCAs and the MAOIs, both of which affect the activity of multiple monoamine neurotransmitters. These medications also interacted with a number of unrelated receptors which led to a substantial burden of side effects. The TCAs antagonize muscarinic cholinergic, H1-histaminic, and alpha-adrenergic receptors, causing constipation, urinary retention, dry mouth, sedation, weight gain, and postural hypotension. In addition to these side effects, the monoamine oxidase inhibitors have the added risk of potentially severe hypertensive crises due to the effects of dietary tyramine, which requires dietary restrictions. $^{25}$

The introduction of the SSRIs marked the beginning of an era of greater selectivity. This class of medication includes fluoxetine, sertraline, paroxetine, fluvoxamine, citalopram, and escitalopram. Binding almost exclusively to the serotonin transporter, these new antidepressants avoided many of the side effects commonly associated with the TCAs and MAOIs. Initially, it was not clear whether activity at a single monoamine transporter affected the efficacy of this class of medication, especially for the treatment of more severely ill patients. A meta-analysis that included 55 double-blind studies which compared an SSRI to nonselective agents (primarily tricyclics), found that SSRIs were slightly less effective than TCAs when given to inpatients, but in general, the two classes were approximately equal. ${ }^{26} \mathrm{~A}$ later meta-analysis also found that TCAs had greater efficacy with inpatients, and also confirmed the superior tolerability of SSRIs. ${ }^{27}$

Bupropion was introduced around the time of the SSRIs. Bupropion is unique, being the only antidepressant which selectively interacts with the norepinephrine and dopamine systems. Bupropion has not been extensively compared to TCAs. A number of small studies have found bupropion to be effective in patients who failed to respond to, or were unable to tolerate a TCA. ${ }^{28,29}$ The most widely cited study which compared bupropion to a TCA found that the TCA desipramine caused more treatment-emergent mood elevation in depressed bipolar patients when added to an ongoing therapeutic regimen of lithium or an anticonvulsant.

Venlafaxine was the first serotonin norepinephrine reuptake inhibitor (SNRI). Like many of the tricyclics, venlafaxine binds to the transporter protein of both norepinephrine and serotonin. Like the SSRIs, venlafaxine avoids side effects associated with antagonism of muscarinic cholinergic, H1-histaminic, and alpha-adrenergic receptors. More recently, duloxetine was introduced, which like venlafaxine and DVS is a SNRI.

Other antidepressants that interact with multiple monoamine systems include nefazodone, which is a weaker serotonin and norepinephrine reuptake inhibitor, but is a 
potent serotonin 5-HT2 receptor antagonist. Nefazodone is rarely used currently due to the small possibility of hepatic injury, which could lead to the need for a liver transplant, or even death. ${ }^{30}$ Mirtazapine is a potent antagonist of central alpha-adrenergic autoreceptors, and heteroreceptors and is an antagonist of serotonin 5-HT2 and 5-HT3 receptors.

A comparison of the efficacy of the SSRIs and the newer dual-reuptake inhibitors is discussed in detail below in the context of evaluating the appropriate place in therapy of DVS.

\section{New indications: pain}

Antidepressants have received attention for the treatment of pain because it is believed that norepinephrine plays an important role in neuropathic pain. Neuropathic pain is non-nociceptive, therefore response to traditional analgesics such as opioids and nonsteroidal anti-inflammatory drugs is substantially reduced. ${ }^{31}$ TCAs, which like SNRIs block the reuptake of serotonin and norepinephrine, are considered first-line agents for most types of neuropathic pain. ${ }^{32}$ These agents work in both depressed and nondepressed patients, and the doses required for neuropathic pain are much smaller than antidepressant doses. Effects are often seen within a few days, as opposed to weeks needed for an antidepressant response.

It is thought that sensitization of neurons in the dorsal horn of the spinal cord can lead to chronic pain. Increased spontaneous activity of the dorsal horn neurons, a decreased threshold, and an increased responsivity to afferent input can cause hyperalgesia (increased sensitivity to pain) and allodynia (a painful response to a usually nonpainful stimulus). Inhibition of the reuptake of serotonin and norepinephrine within the dorsal horn appears to be the mechanism by which TCAs exert their analgesic effect.

Unfortunately, the adverse effect profile makes this class of drugs less than ideal, and the newer, better tolerated SNRIs are being studied for the treatment of pain. Duloxetine, for example, has been approved for the treatment of diabetic neuropathy and fibromyalgia. Venlafaxine, the precursor molecule of DVS, has been found to be effective at treating a number of painful conditions including pain associated with $\mathrm{MDD},{ }^{33}$ and a number of different neuropathic conditions. ${ }^{32}$ A randomized study consisting of 40 patients with painful polyneuropathy found venlafaxine to be as effective as imipramine. ${ }^{34}$

Not all studies have supported the efficacy of SNRIs in the treatment of painful conditions. A recent meta-analysis of eight trials involving the SSRI paroxetine and the SNRI duloxetine failed to find an advantage for the dual action antidepressant. ${ }^{35}$
Overall, both drugs were superior to placebo but the difference was small, of uncertain clinical significance, and may have been due to nonspecific effects related to improvement in mood.

DVS is also being studied for the treatment of pain. A pain scale was included as part of the large multicenter trials that established the efficacy of DVS in MDD. The scale used was the Visual Analog Scale - Pain Intensity (VAS-PI). ${ }^{36}$ The VAS-PI is a straight line, $100 \mathrm{~mm}$ in length, with the left end of the line representing no pain and the right end of the line representing the worst pain. Patients are asked to mark on the line where they think their pain is. The VAS-PI score is determined by measuring in millimeters from the left hand end of the line to the point that the patient marks. The assessment is highly subjective, and this scale is of most value when looking at change within individuals, and is of less value for comparing across a group of individuals at one time point.

Four randomized, double-blind, placebo-controlled trials found significantly greater decreases in the VAS-PI overall scores among subjects taking DVS compared to those taking placebo, ${ }^{9,14,37,38}$ and in a pooled analysis of two additional studies. ${ }^{39}$ Phase II/III studies are currently evaluating DVS in patients with fibromyalgia.

Although pain in not one of the criteria used by DSM-IV to establish a diagnosis of MDD, it is commonly experienced by depressed patients, and plays an important role in the functional impairment brought on by this disease. A cross-sectional study of data from a US national household survey conducted in 1997-1998 identified 1,486 adults who met criteria for MDD or dysthymia. ${ }^{40}$ Chronic pain such as back pain, chronic headache, self-reported arthritis, or unspecified chronic pain was reported by $63 \%$ of this sample.

Depressed individuals in this study with comorbid pain reported more severe psychiatric distress than depressed persons who did not have pain, and had approximately $20 \%$ more visits to medical providers. Unfortunately, despite the increased medical utilization, the patients with comorbid pain were less likely to see a mental health specialist compared to patients without pain.

Individuals with pain, depression, or both who were enrolled in the Health and Retirement Study were evaluated to determine the impact on functioning of pain with unclear pathology. New onset of limitations in activities of daily living and work disability were seen with greater frequency among those who suffered from comorbid pain and depression compared to those with depression alone. Individuals who experienced depression plus pain were three to four times more likely to experience a new limitation in activities of daily living compared to those with depression alone. 
As the field of psychiatry moves from a primary focus on symptoms to a broader view of the patient which includes measures of functioning and quality of life, attention to pain syndromes associated with depression may become increasingly important.

\section{Unmet needs}

Despite the variety of treatment options, helping patients achieve full remission remains challenging. In the largest naturalistic study of depression, the Sequenced Treatment Alternatives to Relieve Depression (STAR*D) project, only about one-third of the participants reached remission after receiving the first level of treatment, which was citalopram as monotherapy. ${ }^{41}$ Those who did not become symptom-free were advanced to additional levels, however, remission rates were progressively lower in each subsequent treatment level: $25 \%$ in level 2 , and for those who did not achieve remission in level $2,12 \%$ to $20 \%$ in level 3 , and $10 \%$ in level 4 . Over the course of all four treatment levels, almost $70 \%$ of those who did not withdraw from the study became symptom-free. However, the rate at which participants withdrew from the trial rose with each level: $21 \%$ withdrew after level 1, 30\% after level 2 , and $42 \%$ after level 3 .

STAR *D used remission as an outcome measure, meaning that patients had to be essentially symptom-free. If response is used as an outcome measure, the success rate tends to be approximately $60 \%-70 \%$. Response indicates that a patient has experienced a reduction in symptoms, and response is formally defined as a reduction in a depression rating scale score of at least $50 \%$. One of the drawbacks of using response as a measure of success, however, is that residual symptoms of depression can cause substantial morbidity, and their presence is associated with a high risk of relapse. ${ }^{42}$

Tolerability can also be a problem with current antidepressant therapy. All newer antidepressants, with the exception of bupropion, carry the risk of inducing sexual side effects, which may, along with other troublesome side effects, contribute to early discontinuation of treatment. ${ }^{43}$ Adherence to medication can be particularly difficult during periods of normal mood when a medication is being used to prevent future episodes. Tolerability becomes increasingly important as the duration of medication use increases.

Another unmet need is for rapid onset of action. While some improvement is possible early in treatment, it generally takes weeks for an antidepressant to have its full effect. ${ }^{44}$ The reason for this delay is unknown. Although antidepressants cause an immediate increase in the activity of monoamine neurotransmitters, it is believed that chronic drug administration drives the production of adaptations in postreceptor signaling pathways, including regulation of neuronal gene expression, which is ultimately responsible for the therapeutic effects. ${ }^{45} \mathrm{~A}$ medication that bypassed the monoamine system, and directly targeted these downstream effects would be likely to have a more rapid onset of action.

In general, currently available antidepressants are effective medications. Nevertheless, there remains the need for new medications with higher remission rates, better tolerability, and a more rapid onset of action. Rather than being a revolutionary drug, DVS more modestly advances our ability to treat depression. DVS expands the limited options available to clinicians to target more than one neurotransmitter, and it does it in a way that avoids interaction with post-synaptic receptors associated with the high side-effect burden of the previous generation of antidepressants.

\section{Clinical evidence with desvenlafaxine}

DVS was studied in phase II and III randomized placebocontrolled trials that supported the US FDA indication for MDD. ${ }^{37-39,46-48}$ Phase II studies, although positive, were not published.

The first phase III study was an eight-week double-blind, placebo-controlled trial that included 480 adult outpatients with MDD. The change from baseline to endpoint in the 17-item Hamilton Rating Scale for Depression (HAM-D17) was used as the primary outcome measure ${ }^{37}$ (Table 4). Subjects were recruited from 25 centers throughout the United States. Secondary efficacy measures used were the Clinical Global Impressions-Improvement scale (CGI-I), Montgomery-Asberg Depression Rating Scale (MADRS), Clinical Global Impressions-Severity of Illness scale (CGI-S), rates of response ( $\geq 50 \%$ decrease of Ham-D17 from baseline) and remission (HAMD-D17 score $\leq 7$ ), and the VAS-PI overall score. Patients were randomly assigned at baseline to one of three fixed doses of DVS (100, 200, or $400 \mathrm{mg}$ per day) or placebo. All patients who completed the study, regardless of treatment group, had the option of enrolling in a long-term, open-label extension study.

After eight weeks of treatment, the mean HAM-D17 scores for DVS $100 \mathrm{mg}$ per day (12.75) and $400 \mathrm{mg}$ per day (12.50) were significantly lower than for placebo (15.31; $\mathrm{p}=0.0038$ and $\mathrm{p}=0.0023$, respectively); for DVS $200 \mathrm{mg}$ per day, the mean score was $13.31(\mathrm{p}=0.0764)$. CGI-I and MADRS results were significant for all groups; CGI-S results were significant with $100 \mathrm{mg}$ per day and $400 \mathrm{mg}$ per day. Response rates were significantly greater for DVS $100 \mathrm{mg}$ per day (51\%) and $400 \mathrm{mg}$ per day (48\%) versus placebo (35\%; 
Table 4 Desvenlafaxine compared to placebo and venlafaxine: adjusted mean change in HAMD I 7 from baseline in six 8-week randomized controlled trials

\begin{tabular}{|c|c|c|c|c|}
\hline Level of evidence & $\begin{array}{l}\text { Once daily drug } \\
\text { dose }(m g)(n)\end{array}$ & $\begin{array}{l}\text { Adjusted mean } \\
\text { change from baseline }\end{array}$ & $\begin{array}{l}\text { p-value vs } \\
\text { placebo }\end{array}$ & Reference \\
\hline \multirow[t]{4}{*}{2} & DVS I00 (II4) & -10.60 & $P=0.0038$ & Demartinis et $\mathrm{al}^{37}$ \\
\hline & DVS 200 (1 I6) & -9.63 & $P=0.0764$ & \\
\hline & DVS 400 (II3) & -10.74 & $P=0.0023$ & \\
\hline & Placebo (I I8) & -7.65 & & \\
\hline \multirow[t]{3}{*}{2} & DVS 200 (I2I) & -12.6 & $P=0.002$ & Septien-Velez et $\mathrm{al}^{38}$ \\
\hline & DVS 400 (I24) & -12.1 & $P=0.008$ & \\
\hline & Placebo (I24) & -9.3 & & \\
\hline \multirow[t]{2}{*}{2} & DVS I00-200 (I20) & -9.6 & $P=0.277$ & Liebowitz et al ${ }^{48}$ \\
\hline & Placebo (I |4) & -8.6 & & \\
\hline \multirow[t]{3}{*}{2} & DVS 50 (I58) & -11.5 & $P=0.018$ & Liebowitz et al ${ }^{147}$ \\
\hline & DVS I00 (157) & -11.0 & $P=0.065$ & \\
\hline & Placebo (I59) & -9.5 & & \\
\hline \multirow[t]{3}{*}{2} & DVS $50(145)$ & -14.4 & $\mathrm{P}<0.00 \mathrm{I}$ & Boyer et a ${ }^{46}$ \\
\hline & DVS I00 (126) & -14.9 & $\mathrm{P}<0.00 \mathrm{I}$ & \\
\hline & Placebo (I38) & -11.5 & & \\
\hline \multirow[t]{4}{*}{2} & DVS 200-400 (226) & $-14.2 \mid$ & $\mathrm{P}<0.00 \mathrm{I}$ & $\begin{array}{l}\text { Lieberman et a }{ }^{39} \\
\text { (pooled analysis) }\end{array}$ \\
\hline & VEN ER 75-I50 (I27) & -14.26 & $P=0.00 I$ & \\
\hline & VEN ER I50-225 (II5) & -14.56 & $\mathrm{P}<0.00 \mathrm{I}$ & \\
\hline & Placebo (245) & -11.87 & & \\
\hline
\end{tabular}

Abbreviations: DVS, desvenlafaxine;VEN ER, venlafaxine ER.

$\mathrm{p}=0.017$ and $\mathrm{p}=0.046$, respectively); the response rate for DVS $200 \mathrm{mg}$ per day was $45 \%(\mathrm{p}=0.142)$. Remission rates were significantly greater for DVS $400 \mathrm{mg}$ per day $(32 \%)$ versus placebo $(19 \% ; \mathrm{p}=0.035)$; remission rates were $30 \%$ for DVS $100 \mathrm{mg}$ per day $(\mathrm{p}=0.093)$ and $28 \%$ for DVS $200 \mathrm{mg}$ per day $(\mathrm{p}=0.126)$.

Treatment with DVS was associated with improvement in some painful symptoms at the $100 \mathrm{mg}$ dose, but for overall pain scores, neither the $200 \mathrm{mg}$ nor the $400 \mathrm{mg}$ dose group was statistically different from placebo. Greater attrition at higher doses early in the study may have made it difficult to measure dose response effects. Furthermore, most patients did not have a high level of pain at baseline, as pain was not an inclusion criterion for this study. Greater benefit may be observed with greater severity of pain at baseline.

The most commonly reported adverse events were nausea, insomnia, somnolence, dry mouth, dizziness, sweating, nervousness, anorexia, constipation, fatigue, and abnormal ejaculation/orgasm. Nausea occurred at the highest frequency $(35 \%, 31 \%$, and $41 \%$ in the DVS $100 \mathrm{mg}, 200 \mathrm{mg}$, and $400 \mathrm{mg}$ groups, respectively, compared with $8 \%$ in the placebo group). Among patients who discontinued due to adverse events, nausea was the most common adverse event cited as the reason for discontinuation.

Four patients had serious adverse events, including one death. One patient in the $100 \mathrm{mg}$ group committed suicide on study day 5 . It is not known whether this patient had taken any of the medication that was dispensed at the baseline visit. Three additional participants were reported to have had serious adverse events. One patient (400 mg) attempted suicide, another had a dystonic reaction from taking promethazine, and one patient in the placebo group experienced chest pain.

Mean increases in blood pressure in the DVS groups were statistically significant when compared with baseline and placebo at all weeks and the final on-therapy evaluation. None of the changes in vital signs were deemed to be of clinical significance. All DVS dosage groups had statistically significant decreases in weight when compared with baseline and placebo. One patient had clinically significant weight loss of greater than $7 \%$ of baseline body weight.

Statistically significant increases from baseline to end point were observed for the following laboratory values: alanine aminotransferase (ALT), aspartate aminotransferase 
(AST), gamma-glutamyl transferase (GGT), bilirubin alkaline phosphatase, fasting total cholesterol, and fasting triglycerides. In general, these changes were not clinically significant. Only four DVS-treated patients were determined to have clinically significant laboratory abnormalities.

Statistically significant increases from baseline in mean heart rate was observed for all DVS treatment groups when compared to placebo. Several small but statistically significant changes in electrocardiogram (ECG) intervals were observed, most of which were attributable to increases in heart rate (shortening of PR and QRS intervals).

Overall, in the first phase III study, DVS was found to have efficacy comparable to other antidepressant medications. Treatment with DVS was generally well tolerated, particularly at the $100 \mathrm{mg}$ dose, with an adverse effect profile similar to other SNRIs. The rates of response $(45 \%-51 \%)$ and remission (28\%-32\%) were consistent with those observed in other trials of short-term antidepressant treatment. ${ }^{49}$

The absence of a statistically significant difference between DVS $200 \mathrm{mg}$ and placebo on the primary outcome measure is curious in light of the significant differences seen with the $100 \mathrm{mg}$ and $400 \mathrm{mg}$ doses. Considering that approximately half of clinical trials of antidepressants that ultimately receive approval fail to show a significant difference between active drug and placebo, ${ }^{50}$ this finding may be related to type II error rather than true lack of efficacy. Lack of separation seems to be particularly likely in fixed dose studies. In support of this interpretation, the DVS $200 \mathrm{mg}$ group demonstrated statistically significant differences from placebo on the key secondary outcome measures (CGI-I, MADRS) as well as on measures of overall functioning.

A similar eight-week phase III randomized, double-blind, parallel group, placebo-controlled multicenter trial conducted in Europe ( 30 centers) and South Africa ( 5 centers) evaluated the $200 \mathrm{mg}$ and $400 \mathrm{mg}$ doses. ${ }^{38}$ As with the first study, the primary efficacy measure was change from baseline on the HAM-D17. Similar secondary measures were used as well. At the final on-therapy evaluation, adjusted mean change from baseline in the HAM-D17 total score was significantly greater with both DVS $200 \mathrm{mg}$ per day $(-12.6 \pm 0.75 ; \mathrm{p}=0.002)$ and DVS $400 \mathrm{mg}$ per day $(-12.1 \pm 0.74 ; \mathrm{p}=0.008)$, compared with placebo $(-9.3 \pm 0.74)$. A significant difference in total score vs. placebo was observed starting at week 4 for both DVS $200 \mathrm{mg}$ per day ( $\mathrm{p} \leq 0.004$ ) and DVS $400 \mathrm{mg}$ per day ( $p \leq 0.049$ ), and were sustained until the end of the study.

Both doses of DVS also performed well on the secondary measures. Response rates were $60 \%, 56 \%$, and $38 \%$ for DVS $200 \mathrm{mg}$ per day, $400 \mathrm{mg}$ per day and placebo, respectively. Significantly more participants treated with DVS $200 \mathrm{mg}$ per day achieved remission compared with placebo (37\% vs 23\%, respectively; $p=0.017)$. Although not statistically significant, remission rates on the HAM-D17 were numerically higher for DVS $400 \mathrm{mg}$ per day than for placebo (34\% vs 23\%, respectively; $p=0.066$ ).

Treatment-emergent adverse events were reported by $70 \%$ of placebo participants, $85 \%$ of DVS $200 \mathrm{mg}$ per day participants and $90 \%$ of DVS $400 \mathrm{mg}$ per day participants. The adverse events reported were similar to the first study. An analysis of change over time found that the side effects tended to resolve as participants continued to take the medication. The incidence of the most common treatmentemergent adverse events (nausea, dry mouth, sweating, dizziness, fatigue, and constipation) was highest during the first week of treatment and decreased rapidly so that from week three onward no major differences were observed between the DVS and placebo treatment groups.

DVS $400 \mathrm{mg}$ per day was associated with small but significant increases from baseline in mean pulse rate and diastolic blood pressure; a significant decrease from baseline in mean body weight was observed for participants in both DVS groups.

Statistically significant changes were seen in the $400 \mathrm{mg}$ group in the following laboratory studies: ALT, AST, GGT, bilirubin, alkaline phosphatase and fasting high-density lipoprotein (HDL) cholesterol. Only the differences in bilirubin (decrease) and alkaline phosphatase (increase) were statistically significant in the $200 \mathrm{mg}$ group. None of the laboratory changes were associated with clinical symptoms, and all were reversed when DVS treatment was discontinued.

As seen in the first study, several small but statistically significant ECG changes were observed in both DVS treatment groups. As before, these changes were attributable to increases in mean heart rate, and were not clinically significant.

The third phase III trial failed to separate from placebo on the primary outcome measure. ${ }^{48}$ This study utilized a $100 \mathrm{mg}$ per day starting dose, with an increase to $200 \mathrm{mg}$ per day at two weeks. The dose could be decreased back to $100 \mathrm{mg}$ for safety or tolerability reasons. It was an eight-week multicenter double-blind randomized trial involving 247 outpatients, and used the same primary and secondary efficacy measures as the two previous trials. Following the initial titration period (days 1-14) the mean daily dose of DVS for the intent-to-treat population was 179.0 to $195.3 \mathrm{mg}$. For those who completed the entire eight-week trial, the mean daily dose was 182.4 to $195.2 \mathrm{mg}$. 
At this point the weight of evidence supported the efficacy and safety of DVS, and substantial advantages of higher doses over lower doses had not been seen. The next study that was undertaken attempted to better establish the minimum effective dose in a three arm study consisting of DVS $100 \mathrm{mg}$, DVS $50 \mathrm{mg}$, and placebo. ${ }^{47}$ This multi-center, double-blind study enrolled 447 outpatients who were treated for eight weeks. The inclusion and exclusion criteria, and primary and secondary efficacy measures were the same as in the previous trials.

DVS $50 \mathrm{mg}$ per day was associated with a significantly greater mean change from baseline on the HAM-D17 $(-11.5)$ compared to placebo $(-9.5 ; \mathrm{p}=0.018)$; the $100 \mathrm{mg}$ dose group $(-11.0)$ did not achieve statistical significance $(\mathrm{p}=0.065)$. The $100 \mathrm{mg}$ group did, however, demonstrate significant improvements compared with placebo on several secondary efficacy measures, including the 6-item Hamilton Depression Rating Scale and the VAS-PI total score.

An important addition to this study was the inclusion of the Discontinuation-Emergent Signs and Symptoms (DESS) checklist, which was used to evaluate adverse events that occurred or worsened during and after the seven-day taper period when the medication was discontinued. Discontinuation-related symptoms are common with many antidepressants, ${ }^{51}$ and may be more common with SNRIs. ${ }^{52}$ In this study, however, the DESS score for both DVS doses appeared to be comparable or lower than DESS scores reported in published studies for other SNRIs and SSRIs. ${ }^{53,54}$ Additionally, neither the tapered DVS $100 \mathrm{mg}$ per day group, nor the group discontinued from DVS $50 \mathrm{mg}$ per day without a taper, had a mean change in DESS score of greater than three points, the threshold defined as a "discontinuation syndrome". .54

Both DVS doses were generally well tolerated. Of note, nausea, which was the most frequently reported adverse event in previous studies, was not among the most commonly reported in this study. Moreover, the rate of nausea associated with DVS during the first week of treatment (at a dose of $50 \mathrm{mg}$ per day) was substantially lower compared with those in a previous study $(22 \%-31 \%)$ in which DVS treatment was initiated at $100 \mathrm{mg}$ per day. ${ }^{37}$ Rates of discontinuation $(3 \%-7 \%)$ due to adverse events in this study were also lower than in the previous studies which used higher doses (11\%-21\%). Withdrawals due to adverse events were evenly distributed throughout the treatment period, whereas previous studies, in which treatment was initiated at doses of $100 \mathrm{mg}$ per day or higher, most discontinuation events occurred during the first two weeks of treatment.
The lower dose strategy was tested in a similar study of 483 subjects conducted in multiple centers throughout Europe and South Africa ${ }^{46}$ Both doses were superior to placebo across all primary and secondary efficacy measures. As in the previous study, the efficacy of the $50 \mathrm{mg}$ and $100 \mathrm{mg}$ doses was comparable to that observed at higher doses, ${ }^{37,38}$ and adverse events were similar to those reported with other SNRIs. ${ }^{55}$ As expected, fewer adverse events were reported compared to studies which used higher doses.

The two $50 \mathrm{mg}$ per day studies found this dose to be effective and well tolerated even without initial titration. Additionally, this dose was associated with minimal side effects upon discontinuation without a taper. A question that arises from these results is whether an even smaller dose would also be effective. Ideally, dose-finding studies test progressively lower doses until an inactive dose is identified, thereby establishing a minimum floor. Thus far $50 \mathrm{mg}$ is the lowest dose tested in a published study.

Two similarly designed studies compared DVS to placebo using venlafaxine ER as an active control. Although individually neither demonstrated statistically significant differences on the primary outcome measure, a pooled analysis supported the superiority of DVS compared to placebo. ${ }^{39}$ One of the studies was done in the United States, and the other in Europe. Both had a high placebo response rate, and in retrospect it appeared that they had not been adequately powered to detect a difference in the setting of this high placebo response rate. The similarities of the protocols allowed the results were to be pooled in order to increase the number of subjects in the analysis, and provide adequate statistical power.

A total of 738 patients were randomly assigned to eight weeks of treatment with placebo (250 patients), DVS (239 patients), or venlafaxine ER (249 patients). The initial target dose of DVS was $200 \mathrm{mg}$ per day with the option to increase to $400 \mathrm{mg}$ per day after study day 28. In the European study venlafaxine ER was dosed between $75 \mathrm{mg}$ per day and $150 \mathrm{mg}$ per day, while in the US study the allowable range was $75 \mathrm{mg}$ per day to $225 \mathrm{mg}$ per day. Because of this difference in dosing guidelines, the venlafaxine ER data was not pooled.

The primary outcome measure was change from baseline in the 17-item Hamilton Rating Scale for Depression (HAM-D17). A statistically significant difference between DVS and placebo was observed at week three, and maintained throughout the treatment period. There were no significant differences between DVS and venlafaxine ER, however the study was not designed to identify differences between these two groups. 
A number of secondary measures were also found to be statistically significant, including the CGI-S, and the visual analog scale for back pain, chest pain, arm/leg/joint pain, and overall pain. Clinical Global Impression Scale Improvement (CGI-I) and improvement in stomach pain were not statistically different from placebo. Adverse effects were those typically seen in other studies, and included nausea, somnolence, dry mouth, and sweating.

The high placebo response rate observed in the two studies reflects the increasing placebo response rate observed in many studies over recent years. A review of controlled trials published in English between January 1981 and December 2000 in which adult outpatients with MDD were randomly assigned to receive medication or placebo found that the placebo response rate has increased by approximately $7 \%$ per decade ${ }^{56}$ Variability was large ranging from approximately $10 \%$ to more than $50 \%$. The placebo response rate in the pooled DVS analysis was $47 \%$.

In summary, desvenlafaxine at the $50 \mathrm{mg}$ dose has been shown to be superior to placebo in treating MDD. While doses as high as $400 \mathrm{mg}$ per day have been tested, there is no evidence that doses higher than $50 \mathrm{mg}$ /day are more effective. In some studies, higher doses did not separate from placebo, whereas lower doses did..$^{37,48}$ The reason for this difference is unclear. A consistent finding, however, is the greater incidence of adverse events at higher doses; the $50 \mathrm{mg}$ dose was the best tolerated. All of the phase III studies using desvenlafaxine for depression have been short term (eight weeks). Long term placebo-controlled maintenance data is not yet available.

With respect to safety and tolerability, the most commonly observed side effects of desvenlafaxine were nausea, dry mouth, somnolence, sweating, constipation and decreased appetite, resulting in statistically significant weight loss ranging from 0.18 to $1.82 \mathrm{~kg}$ over the course of eight weeks.

Cardiovascular side effects were observed which were small, yet statistically significant. Increases in supine pulse rate ranged from 0.69 to 5.79 beats per minute. Increases in systolic blood pressure ranged from 0.61 to $4.05 \mathrm{mmHg}$. Mean increases in diastolic blood pressure ranged from 0.66 to $3.41 \mathrm{mmHg}$. Mean increases in QTc ranged from 0.18 to 7.25 milliseconds. It should be noted that individual patients may experience larger changes, and while it does not appear to be necessary to monitor the ECG, blood pressure should be monitored, as with the other SNRIs.

There were a number of laboratory findings associated with desvenlafaxine treatment. Statistically significant increases were observed in alkaline phosphatase (1.1-8.9 U/L), GGT (1.3-11.0 U/L), AST (1.6-2.9 U/L), ALT (3.9-4.2 U/L), total cholesterol (0.10-0.23 mmol/L), HDL (0.035-0.060 mmol/L), low-density lipoproteins (LDL; $0.05-0.17 \mathrm{mmol} / \mathrm{L}$ ), and triglycerides $(0.11-0.13 \mathrm{mmol} / \mathrm{L})$. Statistically significant decreases were observed in total bilirubin ranging from 0.6 to $2.2 \mathrm{mg} / \mathrm{dL}$. While these test changes were not associated with clinical findings, laboratory monitoring for individuals undergoing treatment with desvenlafaxine may be indicated for individuals with pre-existing liver or lipid abnormalities.

Although there were no observations of desvenlafaxine causing suicidality, like all antidepressants, desvenlafaxine carries the required FDA black box warning on suicidality. Good clinical practice requires close monitoring of any patient treated with antidepressants for emerging suicidality, particularly in severely depressed patients initiating therapy.

\section{Economic evidence}

Due to the high prevalence of MDD, the availability of effective, well tolerated antidepressants, and the diminishing stigma of receiving treatment, medical costs associated with MDD constitute a significant portion of health care expenditures. The need for information on the cost effectiveness of interventions for depression is being driven by rising costs and the scarcity of mental health resources.

Economic evaluations aim to combine costs and patient outcomes in one analysis. Outcome measures may include the cost per success (for example remission), cost per symptom-free day, or total cost, both inpatient and outpatient, over a specified period of time. Although the focus is often on the cost of the antidepressant drug itself, in actuality, drug costs represent only $10 \%$ of the overall economic costs of depression. ${ }^{57}$ Consequently, other factors, such as hospitalization, physician costs, and indirect costs associated with lost productivity must be included in a comprehensive analysis.

Because DVS was introduced only recently, studies involving economic analyses have not yet been performed. Indirect evidence, involving the evaluation of venlafaxine, the parent compound of DVS, suggests that DVS has the potential to be a cost-effective option in the treatment of MDD. Venlafaxine has been compared to both generic SSRIs and the older tricyclic antidepressants, and in most studies has been shown to be the more cost effective agent. ${ }^{21,58-63}$ This is largely driven by the small, though statistically significant advantage that the SNRIs have in bringing about response 
and remission which result in savings that outweigh the higher acquisition costs. ${ }^{64}$ One study concluded that that the cost of an SSRI could be reduced to a few pennies per day, and the cost of a tricyclic to zero before the overall cost of venlafaxine treatment ceased to be lowest. ${ }^{60}$

Some studies found escitalopram, which also has higher acquisition costs than the generic SSRIs, to be more cost effective than venlafaxine, ${ }^{65-67}$ although others did not, ${ }^{61,68,69}$ making this finding less consistent.

The inclusion of the cost of treating medical comorbities in the analysis appears to be important. Some analyses found that there was no cost advantage to treatment with venlafaxine compared to SSRIs until the medical costs of nonpsychiatric care was included in the analysis. ${ }^{62,63}$ This finding may reflect the efficacy of venlafaxine and other SNRIs in the treatment of pain that is frequently seen in patients with MDD.

Looking beyond the cost of the antidepressant itself, agents with a dual mechanism of action are associated with higher rates of remission, more depression free days, and reduced pain-symptom morbidity, which can lead to reduced health service utilization. An important caveat is that the evidence reviewed involved venlafaxine rather than DVS. Although DVS has the theoretical advantage of noradrenergic activity at typical starting doses, whether DVS will show cost advantages similar to venlafaxine remains to be seen, particularly in the setting of the availability of generic venlafaxine.

\section{Dosage and administration}

Desvenlafaxine is available as an ER tablet in the form of desvenlafaxine succinate, a stable salt, which results in bioavailablility of $80 \%$ when taken orally. Each tablet contains $76 \mathrm{mg}$ or $152 \mathrm{mg}$ of desvenlafaxine succinate, equivalent to $50 \mathrm{mg}$ or $100 \mathrm{mg}$ of desvenlafaxine. ${ }^{70}$ The recommended starting and maintenance dose of desvenlafaxine is a $50 \mathrm{mg}$ ER tablet taken orally once daily with or without food. Based on published data, there is no clinical evidence that doses greater than $50 \mathrm{mg}$ per day confer any additional benefit for treatment of MDD, ${ }^{47}$ and higher doses may be associated with greater incidence of adverse events, especially nausea. ${ }^{37,38,48}$ However, some patients may require a higher dose, and Pristiq $^{\circledR}$ is available in both $50 \mathrm{mg}$ and $100 \mathrm{mg}$. Doses as high as $400 \mathrm{mg}$ per day have been shown to be effective. There is also some evidence that higher doses are more effective for pain symptoms. ${ }^{38}$

Because Pristiq $^{\circledR}$ tablets have an ER formulation, the tablet can not be divided, crushed or chewed; thus titration in increments of less than $50 \mathrm{mg}$ has to be done on an every other day basis. Discontinuation of a $50 \mathrm{mg}$ per day dose without a taper was not associated with a discontinuation syndrome, ${ }^{47}$ however, gradual dose reduction from higher doses is recommended.

\section{Place in therapy}

SNRIs, SSRIs, and the other newer antidepressants are all considered first line treatments for MDD. No single antidepressant works best for all patients, and some patients may need to try numerous medications before they find one that is both effective and tolerable. Consequently, it is important to have a broad range of options available.

It is generally believed that all antidepressants approved by the US FDA are similarly effective. ${ }^{71}$ However, because SNRIs block the reuptake of both norepinephrine and serotonin there has been some interest in whether they may have greater efficacy than the SSRIs which only block the reuptake of serotonin. Because DVS has been available for only a short period of time, head-to-head comparisons with other SSRIs have not yet been performed. A number of studies have been published comparing venlafaxine to SSRIs, however, and these have tended to favor the SNRI, but only by small margins.

A metaanalysis combined data from 34 studies comparing venlafaxine to fluoxetine $(n=20)$, paroxetine $(n=8)$, sertraline $(n=3)$, citalopram $(n=2)$, and fluvoxamine $(n=1)$. The primary outcome measure was remission following eight weeks of treatment. The differences numerically favored venlafaxine over SSRIs in 28 studies, with six studies numerically favoring the SSRI over venlafaxine. Overall, venlafaxine therapy was associated with a statistically significant 5.9\% (95\% confidence interval [CI]: 0.038-0.081) advantage. $^{72}$

Tolerability was similar for the two classes of medication. Overall discontinuation rates for any reason were $28 \%$ for the pooled venlafaxine and $27 \%$ for the pooled SSRI treatment groups. A higher percentage (11\%) of venlafaxine-treated patients discontinued therapy because of adverse events compared with SSRIs $(9 \% ; \mathrm{p}=0.0011)$. Discontinuation rates because of lack of efficacy were $4 \%$ for venlafaxine and $5 \%$ for SSRIs.

A similar study that looked at response rather than remission also found a modest advantage for the dual action agents. ${ }^{73}$ This metaanalysis, which included 93 trials with 17,036 subjects, used a broad definition of dual action antidepressant, which included dual reuptake inhibitors, and drugs that affected both the serotonin and norepinephrine 
systems in other ways. The specific drugs included were venlafaxine, duloxetine, milnacipran, mirtazapine, mianserin, and moclobemide.

The average response rate of the dual action antidepressants was $63.6 \%$ compared to $59.3 \%$ for the SSRIs. The number needed to treat was 24 , indicating that 24 patients would need to be treated with dual-action antidepressant drugs instead of SSRIs in order to obtain one additional responder. This number may have underestimated the true comparative advantage of SNRIs due to the broad inclusion of non-SNRI medications.

If a patient demonstrates treatment resistance by failing to respond to a trial of antidepressant therapy, guidance on selecting the next most appropriate step is sparse. Unfortunately, failure to respond to an antidepressant is common. As noted above, in the STAR*D trial, only about $30 \%$ of patients were in remission following up to 12 weeks of therapy with the SSRI citalopram. ${ }^{41}$

If a patient continues to experience depressive symptoms, despite an optimal antidepressant trial, two general strategies exist. The first involves augmentation with a second medication, and the other involves discontinuing the first antidepressant, and switching to a second. ${ }^{74}$ Augmentation requires a patient to take two medications, while switching maintains treatment with a single one. The latter, more simple medication regimen may have advantages with regard to adherence and minimization of side effects.

For patients who are initially given an SSRI antidepressant, switch options include a within-class switch to a second SSRI, or an across-class switch to a medication with a different mechanism of action. Few studies have been carried out comparing within class to across class switches. The largest study was done as part of the STAR*D study in which patients who did not experience remission after 14 weeks of citalopram were randomized to a second SSRI (sertraline), bupropion (a medication with norepinephrine and dopamine activity), or venlafaxine. ${ }^{75} \mathrm{~A}$ total of 727 subjects were enrolled in this study, and no statistically significant differences were found among the three study arms. Remission rates were: sertraline, $17.6 \%$; bupropion, $21.3 \%$; and venlafaxine, $24.8 \%$.

The STAR*D study was powered to detect a $15 \%$ between-group difference in remission rates. In order to increase the power of the statistical analysis, and detect smaller, yet potentially meaningful differences between the two switch strategies, Papakostas and colleagues performed a meta-analysis of data from four clinical trials, which included 1,496 subjects. Subjects in these studies who did not experience remission on various SSRIs were randomized to receive a second SSRI (paroxetine, sertraline, or citalopram) or a non-SSRI antidepressant (venlafaxine, mirtazapine, or bupropion). Patients who received an across-class switch were significantly more likely to experience remission than those who had a within-class switch (pooled risk ratio for remission $1.29 ; \mathrm{p}=0.007)$. The number needed to treat in this analysis was 22 .

DVS was not available when these comparative studies were undertaken. Although one may hypothesize that its performance would be similar to the parent compound venlafaxine, it remains to be established in clinical trials. An advantage that DVS may have is that it is more equal in its effect on serotonin and norepinephrine compared to venlafaxine. Venlafaxine does not have an appreciable effect on the norepinephrine system until it is titrated to approximately 225 to $375 \mathrm{mg}$ per day. ${ }^{76}$ Doses of this magnitude are frequently used in clinical trials, but doses below $100 \mathrm{mg}$ are more typical in routine practice. ${ }^{43}$ Consequently, many patients receiving venlafaxine in a non-research environment are essentially experiencing an SSRI effect. Because DVS blocks the reuptake of both serotonin and norepinephrine at starting doses, patients in real world settings may experience dual reuptake inhibition with greater consistency.

Given the brief duration of DVS availability, its ultimate place in therapy will become more clear over time. As a new SNRI, it may prove to be a valuable addition to available antidepressant medications. The clinical superiority of the dual action antidepressants over many of the SSRIs is a well replicated finding, but the effect size is small. Perhaps more important is the potential for economic advantages over older agents, and efficacy in the treatment of pain. Comorbid pain appears to be common among patients suffering from depression, but despite the serious functional impairment it can cause, it has received little attention until recently. Like duloxetine, treatment with DVS was associated with statistically significant reductions in most pain scales that were used in the registrational trials. SSRIs have not been found to be particularly effective in treating pain, but additional head-to-head comparisons between SSRIs and SNRIs are needed before firm conclusions can be drawn.

Among the newer antidepressants, only duloxetine and DVS block the reuptake of both serotonin and norepinephrine at starting doses. Because only a minority of patients experience remission after an initial trial of an antidepressant, and because it is not possible to know in advance which antidepressant will help a particular patient, a greater number of options can lead to better results. As one of only a limited 
number of SNRIs, DVS has the potential to play a significant role in improving treatment outcomes.

\section{Disclosure}

The authors report no conflicts of interest in this work.

\section{References}

1. Brown TA, Di Nardo PA, Lehman CL, Campbell LA. Reliability of DSM-IV anxiety and mood disorders: implications for the classification of emotional disorders. J Abnorm Psychol. 2001;110(1):49-58.

2. American Psychiatric Association. Diagnostic and Statistical Manual of Mental Disorders. Fourth Ed. Washington, DC: American Psychiatric Association; 1994.

3. World Health Organization. The World Health Report 2002: Reducing Risks. Promoting Healthy Life. Geneva, Switzerland: World Health Organization; 2002.

4. Robins LN, Helzer JE, Croughan J, Ratcliff KS. National Institute of Mental Health Diagnostic Interview Schedule. Its history, characteristics, and validity. Arch Gen Psychiatry. 1981;38(4):381-389.

5. Robins LN, Regier DA. Psychiatric Disorders in America: The Epidemiologic Catchment Area Study. New York, NY: The Free Press; 1991.

6. American Psychiatric Association. Diagnostic and Statistical Manual of Mental Disorders Third Edition: DSM-III. 1st ed. Washington, DC: American Psychiatric Association; 1980.

7. Weissman MM, Livingston BM, Leaf PJ, Florio LP, Holzer CI. Affective disorders. In: Robins LN, Regier DA, editors. Psychiatric Disorders in America: The Epidemiologic Catchment Area Study. New York, NY: The Free Press; 1991. p. 53-80.

8. Kessler RC, McGonagle KA, Zhao S, et al. Lifetime and 12-month prevalence of DSM-III-R psychiatric disorders in the United States. Results from the National Comorbidity Survey. Arch Gen Psychiatry. 1994;51(1):8-19.

9. Kessler RC, Nelson CB, McGonagle KA, Liu J, Swartz M, Blazer DG. Comorbidity of DSM-III-R major depressive disorder in the general population: results from the US National Comorbidity Survey. $\mathrm{Br} J$ Psychiatry Suppl. 1996;(30):17-30.

10. Hirschfeld RM, Keller MB, Panico S, et al. The National Depressive and Manic-Depressive Association consensus statement on the undertreatment of depression. JAMA. 1997;277(4):333-340.

11. Regier DA, Hirschfeld RM, Goodwin FK, Burke JD Jr, Lazar JB, Judd LL. The NIMH Depression Awareness, Recognition, and Treatment Program: structure, aims, and scientific basis. Am J Psychiatry. 1988;145(11):1351-1357.

12. Olfson M, Marcus SC, Druss B, Elinson L, Tanielian T, Pincus HA. National trends in the outpatient treatment of depression. JAMA. 2002;287(2):203-209.

13. Narrow WE, Rae DS, Robins LN, Regier DA. Revised prevalence estimates of mental disorders in the United States: using a clinical significance criterion to reconcile 2 surveys' estimates. Arch Gen Psychiatry. 2002;59(2):115-123.

14. Kessler RC, Berglund P, Demler O, et al. The epidemiology of major depressive disorder: results from the National Comorbidity Survey Replication (NCS-R). JAMA. 2003;289(23):3095-3105.

15. Harris EC, Barraclough B. Suicide as an outcome for mental disorders. A meta-analysis. Br J Psychiatry. 1997;170:205-228.

16. Mathers CD, Loncar D. Projections of global mortality and burden of disease from 2002 to 2030. PLoS Med. 2006;3(11):e442.

17. Murray CJL, Lopez AD. The Global Burden of Disease. A comprehensive assessment of mortality and disability from diseases. injuries and risk factors in 1990 and projected to 2020. Cambridge, MA: Harvard School of Public Health on behalf of the World Health Organization and the World Bank; 1996.

18. Lopez AD, Murray CC. The global burden of disease, 1990-2020. Nat Med. 1998;4(11):1241-1243.
19. Murray CJ. Quantifying the burden of disease: the technical basis for disability-adjusted life years. Bull World Health Organ. 1994;72(3):429-445.

20. American Psychiatric Association. Practice guideline for major depressive disorder in adults. Am J Psychiatry. 1993;150(4):1-26.

21. Trivedi MH, Wan GJ, Mallick R, et al. Cost and effectiveness of venlafaxine extended-release and selective serotonin reuptake inhibitors in the acute phase of outpatient treatment for major depressive disorder. J Clin Psychopharmacol. 2004;24(5):497-506.

22. Biggs JT, Spiker DG, Petit JM, Ziegler VE. Tricyclic antidepressant overdose: incidence of symptoms. JAMA. 1977;238(2):135-138.

23. Gardner DM, Shulman KI, Walker SE, Tailor SA. The making of a user friendly MAOI diet. J Clin Psychiatry. 1996;57(3):99-104.

24. Gaudiano BA, Young D, Chelminski I, Zimmerman M. Depressive symptom profiles and severity patterns in outpatients with psychotic vs nonpsychotic major depression. Compr Psychiatry. 2008;49(5): $421-429$.

25. Kent JM. SNaRIs, NaSSAs, and NaRIs: new agents for the treatment of depression. Lancet. 2000;355(9207):911-918.

26. Anderson IM, Tomenson BM. The efficacy of selective serotonin re-uptake inhibitors in depression: a meta-analysis of studies against tricyclic antidepressants. J Psychopharmacol. 1994;8(4):238-249.

27. Anderson IM. Selective serotonin reuptake inhibitors versus tricyclic antidepressants: a meta-analysis of efficacy and tolerability. $J$ Affect Disord. 2000;58(1):19-36.

28. Ferguson J, Cunningham L, Merideth C, et al. Bupropion in tricyclic antidepressant nonresponders with unipolar major depressive disorder. Ann Clin Psychiatry. 1994;6(3):153-160.

29. Stern WC, Harto-Truax N, Bauer N. Efficacy of bupropion in tricyclic-resistant or intolerant patients. J Clin Psychiatry. 1983;44 (5 Pt 2):148-152.

30. Conway CR, McGuire JM, Baram VY. Nefazodone-induced liver failure. J Clin Psychopharmacol. 2004;24(3):353-354.

31. Lipman AG. Analgesic drugs for neuropathic and sympathetically maintained pain. Clin Geriatr Med. 1996;12(3):501-515.

32. Saarto T, Wiffen PJ. Antidepressants for neuropathic pain. Cochrane Database Syst Rev. 2005;3:CD005454.

33. Bradley RH, Barkin RL, Jerome J, DeYoung K, Dodge CW. Efficacy of venlafaxine for the long term treatment of chronic pain with associated major depressive disorder. Am J Ther. 2003;10(5):318-323.

34. Sindrup SH, Bach FW, Madsen C, Gram LF, Jensen TS. Venlafaxine versus imipramine in painful polyneuropathy: a randomized, controlled trial. Neurology. 2003;60(8):1284-1289.

35. Krebs EE, Gaynes BN, Gartlehner G, et al. Treating the physical symptoms of depression with second-generation antidepressants: a systematic review and metaanalysis. Psychosomatics. 2008;49(3): 191-198.

36. Carlsson AM. Assessment of chronic pain. I. Aspects of the reliability and validity of the visual analogue scale. Pain. 1983;16(1):87-101.

37. DeMartinis NA, Yeung PP, Entsuah R, Manley AL. A double-blind, placebo-controlled study of the efficacy and safety of desvenlafaxine succinate in the treatment of major depressive disorder. $J$ Clin Psychiatry. 2007;68(5):677-688.

38. Septien-Velez L, Pitrosky B, Padmanabhan SK, Germain JM, Tourian KA. A randomized, double-blind, placebo-controlled trial of desvenlafaxine succinate in the treatment of major depressive disorder. Int Clin Psychopharmacol. 2007;22(6):338-347.

39. Lieberman DZ, Montgomery SA, Tourian KA, et al. A pooled analysis of two placebo-controlled trials of desvenlafaxine in major depressive disorder. Int Clin Psychopharmacol. 2008;23(4):188-197.

40. Bao Y, Sturm R, Croghan TW. A national study of the effect of chronic pain on the use of health care by depressed persons. Psychiatr Serv. 2003;54(5):693-697.

41. Trivedi MH, Rush AJ, Wisniewski SR, et al. Evaluation of outcomes with citalopram for depression using measurement-based care in STAR*D: implications for clinical practice. Am J Psychiatry. 2006;163(1):28-40. 
42. Fava GA, Fabbri S, Sonino N. Residual symptoms in depression: An emerging therapeutic target. Prog Neuropsychopharmacol Biol Psychiatry. 2002;26(6):1019-1027.

43. Sullivan PW, Valuck R, Saseen J, MacFall HM. A comparison of the direct costs and cost effectiveness of serotonin reuptake inhibitors and associated adverse drug reactions. CNS Drugs. 2004;18(13):911-932.

44. Nierenberg AA, Farabaugh AH, Alpert JE, et al. Timing of onset of antidepressant response with fluoxetine treatment. Am J Psychiatry. 2000;157(9):1423-1428.

45. Hyman S, Nestler E. Initiation and adaptation: a paradigm for understanding psychotropic drug action. Am J Psychiatry. 1996;153(2):151-162.

46. Boyer P, Montgomery S, Lepola U, et al. Efficacy, safety, and tolerability of fixed-dose desvenlafaxine 50 and $100 \mathrm{mg}$ /day for major depressive disorder in a placebo-controlled trial. Int Clin Psychopharmacol. 2008;23(5):243-253.

47. Liebowitz MR, Manley AL, Padmanabhan SK, Ganguly R, Tummala R, Tourian KA. Efficacy, safety, and tolerability of desvenlafaxine $50 \mathrm{mg} /$ day and $100 \mathrm{mg} /$ day in outpatients with major depressive disorder. Curr Med Res Opin. 2008;24(7):1877-1890.

48. Liebowitz MR, Yeung PP, Entsuah R. A randomized, double-blind, placebo-controlled trial of desvenlafaxine succinate in adult outpatients with major depressive disorder. J Clin Psychiatry. 2007;68(11): 1663-1672.

49. Vis PM, van Baardewijk M, Einarson TR. Duloxetine and venlafaxine-XR in the treatment of major depressive disorder: a meta-analysis of randomized clinical trials. Ann Pharmacother. 2005;39(11):1798-1807.

50. Khan A, Khan SR, Walens G, Kolts R, Giller EL. Frequency of positive studies among fixed and flexible dose antidepressant clinical trials: an analysis of the food and drug administration summary basis of approval reports. Neuropsychopharmacology. 2003;28(3):552-557.

51. Fava M. Prospective studies of adverse events related to antidepressant discontinuation. J Clin Psychiatry. 2006;67(Suppl 4):14-21.

52. Sir A, D'Souza RF, Uguz S, et al. Randomized trial of sertraline versus venlafaxine XR in major depression: efficacy and discontinuation symptoms. J Clin Psychiatry. 2005;66(10):1312-1320.

53. Montgomery SA, Huusom AK, Bothmer J. A randomised study comparing escitalopram with venlafaxine $\mathrm{XR}$ in primary care patients with major depressive disorder. Neuropsychobiology. 2004;50(1):57-64.

54. Rosenbaum JF, Fava M, Hoog SL, Ascroft RC, Krebs WB. Selective serotonin reuptake inhibitor discontinuation syndrome: a randomized clinical trial. Biol Psychiatry. 1998;44(2):77-87.

55. Goldstein DJ, Lu Y, Detke MJ, Wiltse C, Mallinckrodt C, Demitrack MA. Duloxetine in the treatment of depression: a double-blind placebocontrolled comparison with paroxetine. J Clin Psychopharmacol. 2004;24(4):389-399.

56. Walsh BT, Seidman SN, Sysko R, Gould M. Placebo response in studies of major depression: variable, substantial, and growing. JAMA. 2002;287(14):1840-1847.

57. Priest RG. Cost-effectiveness of venlafaxine for the treatment of major depression in hospitalized patients. Clin Ther. 1996;18(2):347-358; discussion 302

58. Doyle JJ, Casciano J, Arikian S, Tarride JE, Gonzalez MA, Casciano R. A multinational pharmacoeconomic evaluation of acute major depressive disorder (MDD): a comparison of cost-effectiveness between venlafaxine, SSRIs and TCAs. Value Health. 2001;4(1):16-31.
59. Einarson TR, Addis A, Iskedjian M. Pharmacoeconomic analysis of venlafaxine in the treatment of major depressive disorder. Pharmacoeconomics. 1997;12(2 Pt 2):286-296.

60. Lenox-Smith A, Conway P, Knight C. Cost effectiveness of representatives of three classes of antidepressants used in major depression in the UK. Pharmacoeconomics. 2004;22(5):311-319.

61. Malone DC. A budget-impact and cost-effectiveness model for second-line treatment of major depression. J Manag Care Pharm. 2007;13(6 Suppl A):S8-S18.

62. Monfared AA, Han D, Sheehy O, Bexton B, Lelorier J. Assessment of Canadian provincial expenditures in depressed patients treated with venlafaxine XR versus SSRIs: the APEX Study. Curr Med Res Opin. 2006;22(1):83-94.

63. Morrow TJ. The pharmacoeconomics of venlafaxine in depression. Am J Manag Care. 2001;7(11 Supp1):S386-S392.

64. Woods SW. Pharmacoeconomic studies of antidepressants: focus on venlafaxine. Depress Anxiety. 2000;12(Suppl 1):102-109.

65. Demyttenaere K, Hemels ME, Hudry J, Annemans L. A cost-effectiveness model of escitalopram, citalopram, and venlafaxine as first-line treatment for major depressive disorder in Belgium. Clin Ther. 2005;27(1): 111-124.

66. Fernandez JL, Montgomery S, Francois C. Evaluation of the cost effectiveness of escitalopram versus venlafaxine XR in major depressive disorder. Pharmacoeconomics. 2005;23(2):155-167.

67. Llorca PM, Fernandez JL. Escitalopram in the treatment of major depressive disorder: clinical efficacy, tolerability and cost-effectiveness vs venlafaxine extended-release formulation. Int J Clin Pract. 2007;61(4):702-710.

68. Sorensen J, Stage KB, Damsbo N, Le Lay A, Hemels ME. A Danish cost-effectiveness model of escitalopram in comparison with citalopram and venlafaxine as first-line treatments for major depressive disorder in primary care. Nord J Psychiatry. 2007;61(2):100-108.

69. Wade AG, Toumi I, Hemels ME. A probabilistic cost-effectiveness analysis of escitalopram, generic citalopram and venlafaxine as a first-line treatment of major depressive disorder in the UK. Curr Med Res Opin. 2005;21(4):631-642.

70. Pristiq [package insert], Madison, NJ: Wyeth Pharmaceuticals; 2008.

71. American Psychiatric Association. Practice guideline for the treatment of patients with major depressive disorder (revision). American Psychiatric Association. Am J Psychiatry. 2000;157(4 Suppl):1-45.

72. Nemeroff CB, Entsuah R, Benattia I, Demitrack M, Sloan DM, Thase ME. Comprehensive analysis of remission (COMPARE) with venlafaxine versus SSRIs. Biol Psychiatry. 2008;63(4):424-434.

73. Papakostas GI, Thase ME, Fava M, Nelson JC, Shelton RC. Are antidepressant drugs that combine serotonergic and noradrenergic mechanisms of action more effective than the selective serotonin reuptake inhibitors in treating major depressive disorder? A meta-analysis of studies of newer agents. Biol Psychiatry. 2007;62(11):1217-1227.

74. Thase ME. Therapeutic alternatives for difficult-to-treat depression: a narrative review of the state of the evidence. CNS Spectr. 2004;9(11):808-816, 818-821.

75. Rush AJ, Trivedi MH, Wisniewski SR, et al. Bupropion-SR, sertraline, or venlafaxine-XR after failure of SSRIs for depression. NEngl J Med. 2006;354(12):1231-1242.

76. Debonnel G, Saint-Andre E, Hebert C, de Montigny C, Lavoie N, Blier P. Differential physiological effects of a low dose and high doses of venlafaxine in major depression. Int J Neuropsychopharmacol. 2007;10(1):51-61.
Core Evidence

\section{Publish your work in this journal}

Core Evidence is an international, peer-reviewed open-access journal evaluating the evidence underlying the potential place in therapy of drugs throughout their development lifecycle from preclinical to postlaunch. The focus of each review is to evaluate the case for a new drug or class in outcome terms in specific indications and patient Submit your manuscript here: http://www.dovepress.com/core-evidence-journal
Dovepress

groups. The manuscript management system is completely online and includes a very quick and fair peer-review system, which is all easy to use. Visit http://www.dovepress.com/testimonials.php to read real quotes from published authors. 